\title{
Sex differences in prevalence of anaemia and iron deficiency in infancy in a large multi-country trial in South-East Asia
}

\author{
Frank T. Wieringa ${ }^{1}$, Jacques Berger ${ }^{2,3}$, Marjoleine A. Dijkhuizen ${ }^{1}$, Adi Hidayat ${ }^{4}$, Nguyen X. Ninh $^{3}$, \\ Budi Utomo ${ }^{5}$, Emorn Wasantwisut ${ }^{6}$ and Pattanee Winichagoon ${ }^{6}$ \\ ${ }^{1}$ University Medical Center Nijmegen, The Netherlands, and Nutrition Research and Development Centre, Bogor, Indonesia \\ ${ }^{2}$ Institute of Research for Development 'Nutrition, Food, Societies', Montpellier, France \\ ${ }^{3}$ National Institute of Nutrition, Hanoi, Vietnam \\ ${ }^{4}$ Trisakti University, Jakarta, Indonesia \\ ${ }^{5}$ University of Indonesia, Jakarta, Indonesia \\ ${ }^{6}$ Institute of Nutrition Mahidol University, Bangkok, Thailand
}

(Received 18 December 2006 - Revised 17 March 2007 - Accepted 10 April 2007)

To evaluate effects of Fe supplementation and sex on the prevalence of anaemia and Fe status in infants in South-East Asia, biochemical data from four parallel, randomized, double-blind trials with Fe and/or Zn supplementation in infants $(n$ 2452) in Indonesia, Thailand and Vietnam was pooled. At recruitment ( 5 months of age), Hb concentrations were slightly but significantly lower in boy infants compared with girl infants $(108.7 \mathrm{~g} / 1$ v. $111.4 \mathrm{~g} / \mathrm{l}, P=0.04)$. At 11 months of age, boy infants not receiving Fe had significantly lower $\mathrm{Hb}(106 \cdot 2 \mathrm{~g} / \mathrm{l} v .111 .0 \mathrm{~g} / \mathrm{l}, P<0 \cdot 001)$ and lower serum ferritin concentrations $(14.3 \mu \mathrm{g} / 1$ v. $21.1 \mathrm{~g} / 1, P<0.001)$ than girl infants not receiving Fe. Consequently, boy infants had a relative risk of $1.6(95 \%$ CI $1.3,2 \cdot 1)$ to be anaemic, and of 3.3 (95\% CI 2.1, 5.0) for having Fe deficiency anaemia compared with girl infants. Fe supplementation significantly increased $\mathrm{Hb}$ concentrations in both boys and girls. There was no sex difference in Fe status in infants receiving Fe for 6 months. This study shows that the markedly higher risk for anaemia and Fe deficiency indicates higher Fe requirements in boy than in girl infants. In South-East Asia, standard infant feeding practices do not provide sufficient $\mathrm{Fe}$ to meet requirements of infants, especially boys. Current daily recommended intake for Fe in infancy is the same for boy and girl infants however. Our findings suggest that in especially the second half of infancy, Fe requirements for boy infants are approximately $0.9 \mathrm{mg} / \mathrm{d}$ higher than for girl infants.

Anaemia: Iron status: Infants: South-East Asia: Deficiency

Fe deficiency is the most prevalent micronutrient deficiency, affecting over three billion people worldwide ${ }^{1}$. Infants and children are especially at risk of Fe deficiency as growth increases nutrient requirements, including $\mathrm{Fe}^{2}$. Fe deficiency not only leads to anaemia, but may, even before the onset of anaemia, cause impairment of psycho-motor development, which is in part irreversible ${ }^{3-5}$. For example, infants with $\mathrm{Hb}$ concentrations $<95 \mathrm{~g} / \mathrm{l}$ at 8 months of age scored significantly lower for locomotor scores at 18 months of age ${ }^{6}$. In many developing countries, over $50 \%$ of infants are anaemic by 1 year of age $\mathrm{e}^{7}$, and blanket Fe supplementation for children is being considered as one option to reduce anaemia prevalence in childhood. However, Fe supplementation may negatively influence $\mathrm{Zn}$ uptake and $\mathrm{Zn}$ status ${ }^{8}$. Moreover, a recent study comparing the effects of Fe supplementation on infants in Sweden and Honduras suggests that $\mathrm{Fe}$ supplementation in Fe-replete infants can cause growth faltering ${ }^{9}$, and Fe supplementation in malarious areas could increase morbidity and mortality ${ }^{10,11}$. Hence, Fe supplementation in infants is not as straightforward as once thought. Furthermore, although sex differences in Fe status and Fe requirements are generally thought to arise only after the menarche, some studies have pointed to substantial sex differences in Fe status in infants ${ }^{12}$ and pre-pubertal children ${ }^{13}$.

On the initiative of UNICEF, four parallel studies on Fe and $\mathrm{Zn}$ supplementation in infants were conducted in South-East Asia (Thailand, Vietnam and Indonesia (two sites)) between 1996 and 2000 to investigate effects of Fe and Zn supplementation on $\mathrm{Fe}$ and $\mathrm{Zn}$ status and growth. All trials were randomized, placebo-controlled, double-blind trials. A shared core-protocol was used, specifying basic characteristics for the trials, and allowing pooling of data after completion of the trials. Main outcomes for each site were Fe status, Zn status and growth and these will be reported elsewhere. The aim of the present analysis of the pooled database was to investigate sex differences in infants with respect to anaemia and $\mathrm{Fe}$ deficiency prevalence and efficacy of $\mathrm{Fe}$

Abbreviations: INMU, Institute of Nutrition, Mahidol University, Bangkok; IRD, Institute of Research for Development, Montpellier; NIN, National Institute of Nutrition, Hanoi; NRDC, Nutrition Research and Development Centre, Bogor; UT/UI, University of Trisakti and University of Indonesia; SEAMTIZI, SouthEast Asia Multi-country Trial on Iron and Zinc supplementation in Infants study group.

* Corresponding author: Dr. F.T. Wieringa, fax 3120 6168226, email wieringa@tiscali.nl 
supplementation in view of earlier reports on differences in $\mathrm{Fe}$ status between boys and girls.

\section{Materials and methods \\ Core protocol and design}

The core protocol of the South-East Asia Multi-country Trial on Iron and Zinc supplementation in Infants (SEAMTIZI) was developed in a meeting with all principal investigators, prior to the start of the studies. Agreements were made on the dosage and chemical form of the $\mathrm{Fe}$ and $\mathrm{Zn}$ supplement (10 $\mathrm{mg} \mathrm{Fe}$ and/or $10 \mathrm{mg} \mathrm{Zn} / \mathrm{d}$, both as sulphate salts), the age of recruitment (between 4 and 6 months of age), the duration of supplementation ( 6 months), the design of the studies ( $2 \times 2$ factorial), and core measurements to be included (concentrations of $\mathrm{Hb}$ and $\mathrm{Zn}$, weight and height). At the time of the studies, national policies recommended exclusive breastfeeding for the first 4 months, so it was decided to start supplementation after 4 months of age.

\section{Description of study sites}

The research in Thailand was conducted by the Institute of Nutrition, Mahidol University (INMU) in Khon-kaen province in the north-east of Thailand ${ }^{14}$. Infants were recruited from 106 rural villages. A survey prior to the study showed the prevalence of anaemia in infants aged 4-6 months to be about $50 \%$ in this area. Supplements were given daily by the mother under supervision of health volunteers participating in the study.

The research in Vietnam was conducted by the National Institute of Nutrition (NIN), Hanoi and the Institute of Research for Development (IRD), Montpellier, France, in the rural Que Vo district, in Bac Ninh province in the northwest of Vietnam ${ }^{15}$. Infants were recruited from 120 villages. Similar to the other study areas, most people depend on farming as the main source of income. A recent study showed that approximately $60 \%$ of infants are anaemic in this area ${ }^{16}$. Supplementation was given daily by trained field workers especially recruited for the study.

The research in Indramayu, Indonesia was conducted by the University of Trisakti and University of Indonesia (UT/UI), in a rural area in the province of Indramayu in West Java. Supplements were given $6 \mathrm{~d} /$ week by the village health workers participating in the study.

The research in Bogor District, Indonesia was conducted by the Nutrition Research and Development Centre (NRDC) in Bogor district, West Java ${ }^{17}$. Infants were recruited from six rural villages. In an earlier study in the same area, about $50 \%$ of the infants were anaemic, and $20 \%$ had low plasma $\mathrm{Zn}$ concentrations ${ }^{7}$. Supplements were given $5 \mathrm{~d} /$ week by the health volunteers recruited for the study.

\section{Subjects and procedures}

Mothers of eligible infants were invited to participate in the study, informed of the procedures and purpose of the study, and informed consent was obtained. Infants were assigned to one of the four supplementation groups on the basis of individual randomization, following a computer-generated allocation list using blocks of twelve. Three of the four sites gave a high-dose vitamin A capsule to all infants prior to the study, with one site giving 50.000 IU (INMU) and two sites giving 100.000 IU vitamin A (NIN and UT/UI). These sites also took baseline blood samples in all (NIN), or a subsample of the infants (INMU, UT/UI). Exclusion before recruitment was on grounds of chronic or severe illness, severe clinical malnutrition, or congenital anomalies. In addition, infants with $\mathrm{Hb}$ concentrations $<70 \mathrm{~g} / \mathrm{l}$ were not included, but referred to the health centre for Fe supplementation therapy. After 6 months of supplementation, a blood sample of the infant was taken for biochemical assessment of nutritional status. All infants with a $\mathrm{Hb}$ concentration of $<110 \mathrm{~g} / \mathrm{l}$ were given Fe supplementation treatment at the end of the study. All study sites received ethical approval from their respective ethical boards.

\section{Supplements}

Both Fe and $\mathrm{Zn}$ were supplemented as sulphate salts in a sugarbased syrup, with $15 \mathrm{mg}$ vitamin $\mathrm{C} / \mathrm{ml}$ added. Infants received either $\mathrm{Fe}(10 \mathrm{mg} / \mathrm{d}), \mathrm{Zn}(10 \mathrm{mg} / \mathrm{d}), \mathrm{Fe}+\mathrm{Zn}(10 \mathrm{mg}$ each/d) or placebo as $2 \mathrm{ml}$ syrup, $5-7 \mathrm{~d} /$ week according to site. Supplements for all sites were made by the same pharmaceutical company (PT. Kenrose, Jakarta, Indonesia) in cooperation with UNICEF-Jakarta. Supplementation was double-blind, and the supplements were coded with a letter at the production site. The code was made known only after all subjects had completed the trials and biochemical analyses were completed.

\section{Biochemical analyses}

Blood samples were obtained either by venepuncture (INMU, NIN, NRDC) or heel prick (UT/UI). Hb concentrations were measured by standard cyanmethaemoglobin method (INMU, NIN, NRDC) or Hemocue (UT/UI). Serum (INMU, NIN) or plasma (NRDC) ferritin concentrations were measured with ELISA. Anaemia was defined as a $\mathrm{Hb}$ concentration $<110 \mathrm{~g} / \mathrm{l}$, and Fe deficiency anaemia was defined as anaemia combined with a ferritin concentration $<12 \mu \mathrm{g} / 1^{18}$.

\section{Statistical analysis}

The effect of supplementation on biochemical indicators was investigated using a general linear model controlling for site and sex, using a full factorial model. Ferritin concentrations were transformed to natural logarithms to achieve normality. Differences between boys and girls were analysed with ANCOVA, controlling for site and age, and effect sizes were calculated from estimated means, using the full factorial model. Differences in prevalence of anaemia and Fe deficiency among groups were analysed using $\chi^{2}$ statistics.

Baseline biochemistry was not available for all subjects. One site (NRDC) did not take baseline blood samples, and two sites (INMU, UT/UI) did baseline biochemistry in subgroups only. However, the subgroup of subjects with baseline blood samples in the pooled analysis did not differ from the other subjects in end-point indicators of micronutrient status or anthropometry. 


\section{Results}

Of the 2604 recruited infants, 2452 completed the study (86\%; Fig. 1). Although there were significant differences at recruitment among the different sites in several parameters, including $\mathrm{Hb}$ concentrations, there were no significant differences among the four supplementation groups at recruitment in the pooled database. However, there were significant differences in Fe status between boy and girl infants at recruitment, when the infants had a mean age of 5.2 months (SD 0.9) (all infants). Boy infants had significantly lower $\mathrm{Hb}$ concentrations than girls (108.7 and $111.4 \mathrm{~g} / \mathrm{l}$ respectively, all groups combined; $P=0.04$, ANCOVA controlling for age and site), and boy infants also had a significantly higher prevalence of anaemia $\left(54.3 \%\right.$ and $47.4 \%$ respectively, $P<0.01$, Pearson $\left.\chi^{2}\right)$ at recruitment.

As reported earlier, $\mathrm{Fe}$ supplementation significantly improved $\mathrm{Hb}$ concentrations $(P<0 \cdot 001)$, with a mean estimated effect size of $9.4 \mathrm{~g} / \mathrm{l}(95 \% \mathrm{CI} 8.1,10 \cdot 7)$ in infants receiving $\mathrm{Fe}$ compared with infants not receiving $\mathrm{Fe}^{19}$. Hb concentrations were higher in both the $\mathrm{Fe}$ and $\mathrm{Fe}+\mathrm{Zn}$ groups compared with the placebo and $\mathrm{Zn}$ groups $(P<0.001)$. Sex however significantly affected end-point Hb concentrations ( $P<0.001$; Fig. 2). End-point $\mathrm{Hb}$ concentrations were the same in boys and girls receiving Fe (118.2 and 118.4 g/l respectively; Table 1), but significantly lower in boys not receiving Fe compared with girls not receiving $\mathrm{Fe}(106.2$ and $111.0 \mathrm{~g} / \mathrm{l}$ respectively, $P<0.001$, ANOVA controlling for age, site and $\mathrm{Zn}$ supplementation, Table 1). Hence, the estimated effect size of Fe supplementation on end-point $\mathrm{Hb}$ concentrations in boys was $12.0 \mathrm{~g} / 1 \mathrm{l}(95 \% \mathrm{CI}$ $10 \cdot 2,13 \cdot 8)$ whereas in girls it was only $6.8 \mathrm{~g} / 1$ (95\% CI 4.9, 8.7).

The same sex-specific effect was observed for plasma ferritin concentrations. At recruitment, ferritin concentrations were significantly higher in girl infants than in boy infants (geometric means 46.9 and 32.4 respectively, $P<0.001$, ANOVA controlling for age and site). At the end of the supplementation period, ferritin concentration had declined in the infants not receiving $\mathrm{Fe}$, with boy infants still having significantly lower ferritin concentrations than girl infants (geometric means $14.4 \mu \mathrm{g} / \mathrm{l}$ (95\% CI $13 \cdot 1,15 \cdot 7 \mu \mathrm{g} / \mathrm{l})$ and $21.4 \mu \mathrm{g} / \mathrm{l}$ (95\% CI $19 \cdot 4,23 \cdot 5 \mu \mathrm{g} / \mathrm{l})$ respectively, $P<0.001)$. In contrast, there was no statistically significant difference in end-point ferritin concentration between boys and girls receiving $\mathrm{Fe}$ (geometric means $44.2(95 \%$ CI $40 \cdot 2,48 \cdot 5)$ and $50 \cdot 2 \mu \mathrm{g} / 1 \quad(95 \% \mathrm{CI}$ $46 \cdot 0,55 \cdot 8)$ respectively, $P=0 \cdot 28$, Table 1$)$.

The lower $\mathrm{Hb}$ and ferritin concentrations in boy infants not receiving Fe resulted in a much higher prevalence of anaemia and $\mathrm{Fe}$ deficiency anaemia compared with girl infants not receiving $\mathrm{Fe}$ (Table 1) at the end of the supplementation period, when the infants were on average 11 months old. Overall, in the infants not receiving $\mathrm{Fe}$, boys had a relative risk for anaemia of $1.6(95 \%$ CI $1.3,2.1)$, and a relative risk for having Fe deficiency anaemia of $3 \cdot 3$ (95\% CI $2 \cdot 1$, $5 \cdot 0)$ compared with girls at the end of the supplementation period (Table 2). Similarly, Fe deficiency, as indicated by a ferritin concentration $<12 \mu \mathrm{g} / \mathrm{l}$ regardless of $\mathrm{Hb}$ concentrations, was also significantly more prevalent in boy infants not receiving $\mathrm{Fe}$ compared with girl infants not receiving $\mathrm{Fe}$ (42.5\% v. $21.4 \%, P<0.001)$ with boys having a relative risk of 2.7 (95\% CI $1.9,3.8)$ of being Fe deficient compared with girls.

Interestingly, in the subgroup of infants in which blood samples were taken at recruitment (mean age of these infants 5.6 months), differences in $\mathrm{Hb}$ concentrations between boy and girl infants were already statistically significant, but less distinct than at 11 months of age. Furthermore, boy infants not receiving Fe had a decrease in $\mathrm{Hb}$ concentrations over the study period from $108.4 \mathrm{~g} / \mathrm{l}$ to $106.2 \mathrm{~g} / \mathrm{l}$ (placebo and $\mathrm{Zn}$ groups combined), whereas $\mathrm{Hb}$ concentrations of girl infants not receiving Fe decreased only slightly over the study period $(111.8 \mathrm{~g} / \mathrm{l}$ to $111.0 \mathrm{~g} / \mathrm{l}$, Table 1$)$. Infants not receiving $\mathrm{Fe}$, and who were anaemic at 5 months of age had a significantly higher risk of also being anaemic at 11 months compared with those who were not anaemic at 5 months (odds ratio $2 \cdot 1,95 \%$ CI $1.5,3 \cdot 0 ; \chi^{2}$, placebo and $\mathrm{Zn}$ groups combined). Boy infants had a significantly higher risk to remain anaemic than girls (32\% of the boys remained anaemic

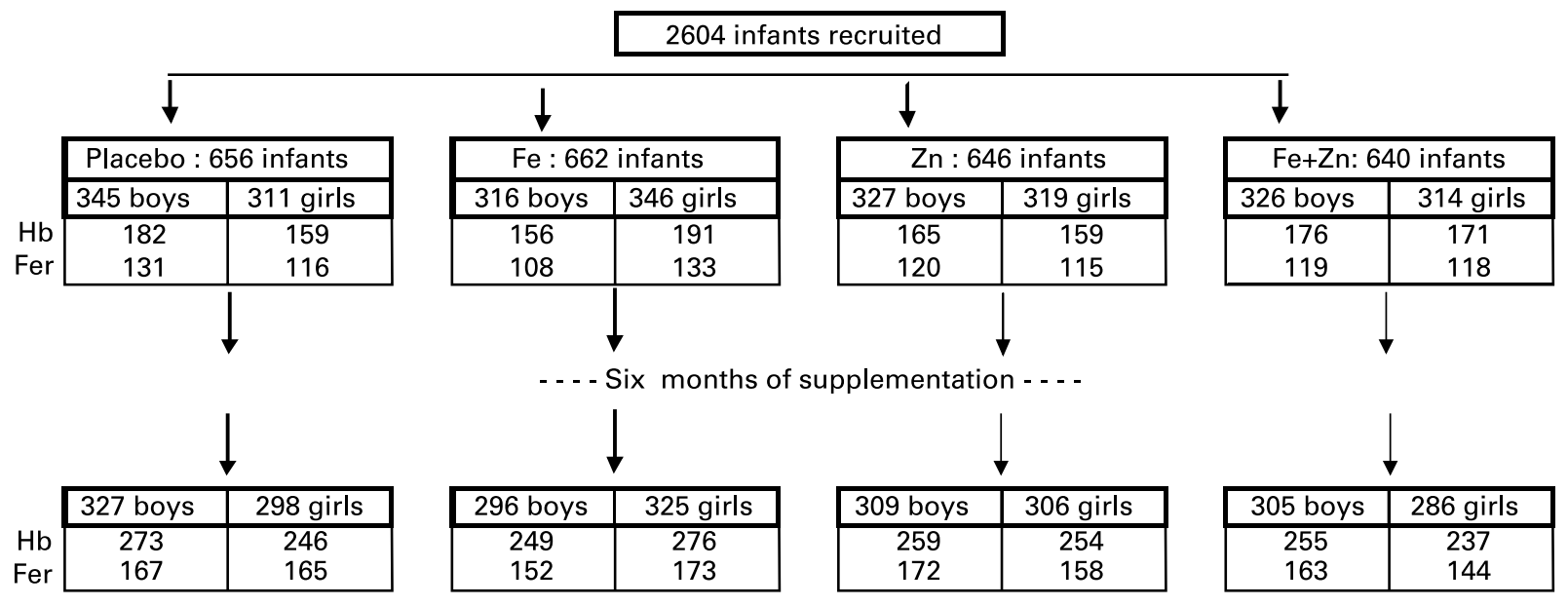

2452 infants completed the study

Fig. 1. Trial profile of the study and the number of blood samples available for haemoglobin (Hb) and ferritin (Fer) determination. 


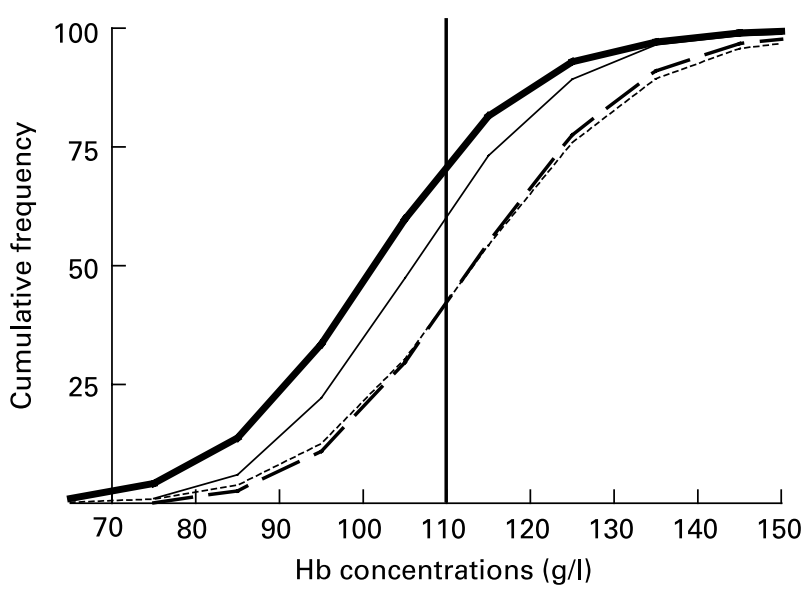

Fig. 2. Cumulative frequency of final $\mathrm{Hb}$ concentrations $(\mathrm{g} / \mathrm{l})$ in boy and girl infants receiving $\mathrm{Fe}$ (boy, $--;$ girl, $\cdots \cdots)(P=0.7)$ or not (boy, $---;$ girl, ---$)$ $(P<0.001)$ for 6 months. The vertical line indicates the current cut-off for anaemia in infants at $110 \mathrm{~g} / \mathrm{l}$.

v. $19 \%$ of the girls). Vice versa, girls had a significantly higher chance of remaining non-anaemic ( $28 \%$ of the boys and $41 \%$ of the girls remained non-anaemic).

\section{Discussion}

In this pooled analysis of data from four large trials on the effects of $\mathrm{Fe}$ and $\mathrm{Zn}$ supplementation on nutritional status in infants, we found significant differences in Fe status between boy and girl infants. Prevalences of anaemia and Fe deficiency at the end of the study were significantly higher in boy infants not receiving $\mathrm{Fe}$ than in girl infants not receiving Fe. After Fe supplementation however, boys and girls achieved similar $\mathrm{Hb}$ concentrations.

At recruitment, when the infants where approximately 5 months of age, the sex difference in $\mathrm{Hb}$ concentrations and $\mathrm{Fe}$ status was already present, but not as distinct as at the end of the study. Hence the largest part of the difference in $\mathrm{Hb}$ concentrations between boy and girl infants not receiving Fe developed during the second half of infancy. It is important to note in this context that it is unlikely that there is a cultural bias towards girls in the three countries that could cause such a sex difference in nutritional status ${ }^{20}$. Moreover, sex differences in anaemia prevalence and Fe status in infancy have been reported from other regions as well, for example the UK and Sweden ${ }^{12,13}$. As both girls and boys achieved similar $\mathrm{Hb}$ concentrations after Fe supplementation, there is no reason to surmise physiological sex differences, e.g. in the physiological ranges of $\mathrm{Fe}$ status indicators or in $\mathrm{Hb}$ set-points. Furthermore, as the infants received a relatively low dose of $\mathrm{Fe}$, close to the RDA, the ranges in $\mathrm{Hb}$ and ferritin concentrations after Fe supplementation probably reflect the physiological ranges, and are not due to Fe overdosing.

The most likely explanation for the findings of the present study is that these boy infants experienced a stronger decline in Fe status during the second half of infancy compared with girl infants, due to higher Fe requirements. The low ferritin concentrations at the end of the study in the boy infants not receiving $\mathrm{Fe}$ further strengthens this interpretation. One reason for higher Fe requirements in boy infants could be the higher growth rate of boy infants. The role of $\mathrm{Fe}$ in growth is complex however. Fe supplementation has been shown to improve length and ponderal growth in some studies ${ }^{2}$, but may also negatively affect growth, especially in Fe-replete children ${ }^{9}$. Regardless of the underlying mechanism, important implications are that boy infants are more at risk for anaemia and Fe deficiency than girl infants, and that the recommendations for RDA of $\mathrm{Fe}$ for infants should either reflect these sex differences, or be high enough to ensure adequate intake of Fe for boy infants. Currently, RDA for boy and girl infants under the age of 1 year are the same however, ranging from 6 to $10 \mathrm{mg} / \mathrm{d}^{21-23}$.

Although transferrin receptor concentrations were not measured in this study, hampering accurate estimation of total body $\mathrm{Fe}$, a very rough estimation of the extra $\mathrm{Fe}$ requirement for boy infants can be made, using the differences in ferritin concentrations at the end of study between boy and girl infants not receiving $\mathrm{Fe}$. Ferritin concentrations in the range 15 to $300 \mu \mathrm{g} / \mathrm{l}$ reflect $\mathrm{Fe}$ stores, with $1 \mu \mathrm{g} / \mathrm{l}$ serum ferritin reflecting $140 \mu \mathrm{g} / \mathrm{kg}$ body weight stored $\mathrm{Fe}^{24}$. Models using this relationship have been shown to predict effects of Fe supplementation on Fe status indices accurately ${ }^{24}$. The difference in ferritin concentrations between boy and girl infants not receiving $\mathrm{Fe}$ at the end of the study $(7 \mu \mathrm{g} / \mathrm{l})$ would correspond to a difference of stored Fe of $8.3 \mathrm{mg}$ (mean body weight $8.5 \mathrm{~kg}$ ). To account for this difference over a 6-month period, assuming that only $5 \%$ of the ingested $\mathrm{Fe}$ is absorbed, boys would need to consume $166 \mathrm{mg}$ more Fe than girls or approximately $0.9 \mathrm{mg} / \mathrm{d}$, or $>10 \%$ higher than most current recommendations. Isotope studies on absorption of intrinsically labelled microencapsulated $\mathrm{Fe}$ fumerate (sprinkles) showed absorption percentages from 4 to $9 \%$. The estimate of $0.9 \mathrm{mg} / \mathrm{d}$ extra Fe for boy infants is a conservative estimate, as Fe body stores are considered depleted at serum ferritin concentrations $<15 \mu \mathrm{g} / \mathrm{l}$, and we do not know at what time point the boy infants became depleted. Clearly, more research specifically investigating $\mathrm{Fe}$ requirements in infants taking these sex differences into account is urgently needed, as the current study was not designed to investigate this. The current study clearly shows however that, with the assumption that infants of both sexes have access to the same diets, Fe needs are higher in boy than in girl infants, and that under 'normal' conditions in three countries in South-East Asia standard infant feeding practices do not meet the Fe requirements, especially of boys but also of girls. These findings are likely to be valid for most developing countries.

Furthermore, this study shows that although Fe supplementation was very effective in eliminating $\mathrm{Fe}$ deficiency anaemia, with less than $3 \%$ of the infants receiving $\mathrm{Fe}$ still having Fe deficiency anaemia at the end of the 6-month supplementation period. The addition of vitamin $\mathrm{C}$ to the supplement syrups may have improved absorption of the ferrous sulphate, but could not prevent the decrease in $\mathrm{Fe}$ status in the placebo group, perhaps because the syrup was given in one daily dose, minimizing the effect of vitamin $\mathrm{C}$ on dietary $\mathrm{Fe}$ absorption. Despite $\mathrm{Fe}$ supplementation, anaemia prevalence remained high at $29 \%$. Various other causes may well underlie the non-Fe deficient anaemia still present after 6 months of Fe supplementation, including haemoglobinopathies such as $\mathrm{Hb} \mathrm{E}$ and thalassaemia, and other micronutrient deficiencies such as vitamin $B_{12}$ or vitamin $A$ deficiency $^{26}$. The prevalence of haemoglobinopathies is 
Table 1. $\mathrm{Hb}$ and ferritin concentrations in boy and girl infants at recruitment and after 6 months of supplementation

\begin{tabular}{|c|c|c|c|c|c|c|c|c|}
\hline & \multicolumn{4}{|c|}{ Not receiving $\mathrm{Fe}$} & \multicolumn{4}{|c|}{ Receiving $\mathrm{Fe}$} \\
\hline & \multicolumn{2}{|c|}{ Boy infants } & \multicolumn{2}{|c|}{ Girl infants } & \multicolumn{2}{|c|}{ Boy infants } & \multicolumn{2}{|c|}{ Girl infants } \\
\hline & Mean/median & SD/IQR & Mean/median & SD/IQR & Mean/median & SD/IQR & Mean/median & SD/IQR \\
\hline \multicolumn{9}{|l|}{ Recruitment } \\
\hline $\mathrm{Hb}(\mathrm{g} / \mathrm{l})$ & $108 \cdot 5^{\mathrm{b}}$ & 14.9 & 111.8 & $15 \cdot 4$ & $108 \cdot 8^{b}$ & 13.4 & $110 \cdot 9$ & $14 \cdot 3$ \\
\hline$n$ & 347 & & 318 & & 332 & & 362 & \\
\hline Anaemia (\%) & $53 \cdot 6^{d}$ & & $45 \cdot 3$ & & $55 \cdot 1^{d}$ & & $49 \cdot 2$ & \\
\hline$<105 \mathrm{~g} / \mathrm{l}(\%)$ & $39 \cdot 2^{d}$ & & $32 \cdot 1$ & & $41 \cdot 6^{\mathrm{d}}$ & & 34.5 & \\
\hline Ferritin $\left(\mu \mathrm{g} / \mathrm{l}^{\mathrm{a}}\right.$ & $32 \cdot 11^{c}$ & $13 \cdot 9-52 \cdot 1$ & $41 \cdot 8$ & $25 \cdot 3-68 \cdot 7$ & $29 \cdot 4^{\mathrm{C}}$ & $16 \cdot 5-55 \cdot 6$ & $42 \cdot 2$ & $20 \cdot 7-76 \cdot 1$ \\
\hline$n$ & 251 & & 231 & & 227 & & 251 & \\
\hline$<20 \mu \mathrm{g} / \mathrm{l}(\%)$ & $35 \cdot 1^{d}$ & & $16 \cdot 9$ & & $33.9^{d}$ & & $22 \cdot 3$ & \\
\hline Fe deficiency anaemia (\%) & $15 \cdot 1^{d}$ & & $4 \cdot 8$ & & $12 \cdot 3^{\mathrm{d}}$ & & $4 \cdot 8$ & \\
\hline \multicolumn{9}{|l|}{ End of supplementation } \\
\hline $\mathrm{Hb}(\mathrm{g} / \mathrm{l})$ & $106 \cdot 2^{e}$ & $16 \cdot 0$ & $111 \cdot 0^{\mathrm{g}}$ & $15 \cdot 1$ & $118 \cdot 2$ & $16 \cdot 0$ & $118 \cdot 4$ & $17 \cdot 5$ \\
\hline$n$ & 532 & & 500 & & 504 & & 513 & \\
\hline Anaemia (\%) & $61 \cdot 8^{t}$ & & $49 \cdot 8^{\mathrm{h}}$ & & $28 \cdot 8$ & & $29 \cdot 8$ & \\
\hline$<105 \mathrm{~g} / \mathrm{l}(\%)$ & $47 \cdot 0^{f}$ & & $32 \cdot 8^{\mathrm{h}}$ & & $17 \cdot 9$ & & $20 \cdot 3$ & \\
\hline Ferritin $(\mu \mathrm{g} /)^{\mathrm{a}}$ & $14 \cdot 3^{e, g}$ & $7 \cdot 7-26 \cdot 6$ & $21 \cdot 1^{\mathrm{g}}$ & $13 \cdot 2-33 \cdot 0$ & 46 & $26 \cdot 0-79 \cdot 8$ & $50 \cdot 7$ & $34.4-84.9$ \\
\hline$n$ & 339 & & 323 & & 315 & & 317 & \\
\hline$<20 \mu \mathrm{g} / \mathrm{l}(\%)$ & $65 \cdot 8^{\mathrm{f}, \mathrm{h}}$ & & $47 \cdot 7^{\mathrm{h}}$ & & 14.9 & & $9 \cdot 8$ & \\
\hline Fe deficiency anaemia (\%) & $27 \cdot 9^{f, h}$ & & $10 \cdot 6^{\mathrm{h}}$ & & $2 \cdot 2$ & & 1.3 & \\
\hline
\end{tabular}

Anaemia was defined as haemoglobin $<110 \mathrm{~g} /$, and iron deficiency anaemia as anaemia combined with a ferritin concentration $<12 \mu \mathrm{g} / \mathrm{l}$

${ }^{a}$ Ferritin concentrations were transformed to natural logarithms prior to statistical analysis.

Significantly different from girl infants at recruitment: ANOVA, controlling for age and site ${ }^{\mathrm{b}} P=0.041 ;{ }^{\mathrm{c}} P<0.01$ and ${ }^{\mathrm{d}} \mathrm{Chi}-\mathrm{square}, P<0.01$

Significantly different from girl infants not receiving iron: ANOVA, controlling for age, zinc supplementation and site ${ }^{\mathrm{e}} P<0.01 ;{ }^{\mathrm{t}} \mathrm{Ch}$-square, $P<0.01$

Significantly different from infants receiving iron: ANOVA, controlling for age, zinc supplementation and site ${ }^{g} P<0.01 ;{ }^{\mathrm{h}}$ Chi-square, $P<0.01$ 
Table 2. Prevalence of anaemia and Fe deficiency anaemia in boy and girl infants receiving $\mathrm{Fe}$ or not, and relative risks for boy infants as compared to girl infants

\begin{tabular}{|c|c|c|c|c|c|c|c|c|}
\hline & \multicolumn{4}{|c|}{ Anaemia* } & \multicolumn{4}{|c|}{ Iron deficiency anaemia* } \\
\hline & \multicolumn{2}{|c|}{ Prevalence } & \multicolumn{2}{|c|}{$\begin{array}{c}\text { Relative risk } \\
\text { (prevalence ratio) }\end{array}$} & \multicolumn{2}{|c|}{ Prevalence } & \multicolumn{2}{|c|}{$\begin{array}{c}\text { Relative risk } \\
\text { (prevalence ratio) }\end{array}$} \\
\hline & Cases $/ n$ & Percent & Risk & $95 \% \mathrm{Cl}$ & Number & Percent & Risk & $95 \% \mathrm{Cl}$ \\
\hline \multicolumn{9}{|c|}{ Infants not receiving $\mathrm{Fe}$} \\
\hline Boys & $329 / 532$ & $61 \cdot 8$ & 1.63 & $1.28,2.09$ & $94 / 339$ & $27 \cdot 9$ & 3.28 & $2.14,5.03$ \\
\hline Girls & $249 / 500$ & $49 \cdot 8$ & & & $34 / 323$ & $10 \cdot 6$ & & \\
\hline \multicolumn{9}{|c|}{ Infants receiving Fe } \\
\hline Boys & $145 / 504$ & $28 \cdot 8$ & 0.95 & $0.73,1.25$ & $7 / 315$ & $2 \cdot 2$ & 1.79 & $0.52,6 \cdot 17$ \\
\hline Girls & $153 / 513$ & $29 \cdot 8$ & & & $4 / 317$ & 1.3 & & \\
\hline
\end{tabular}

estimated to be between 5 and $60 \%$ in the region, with very large regional differences ${ }^{27}$. Sub-optimal vitamin A nutrition is also prevalent in the region, and may contribute to non-Fe deficient anaemia, as vitamin $\mathrm{A}$ has been shown to play a role in the utilization of $\mathrm{Fe}^{26,28}$. Furthermore, chronic lowgrade inflammation such as caused by intestinal parasites might also contribute to lower $\mathrm{Hb}$ concentrations independently of $\mathrm{Fe}$ status ${ }^{29}$. As apparent from this study, the problem of non-Fe deficient anaemia in infants is an important issue in this region, and warrants further research.

To conclude, this study shows that, regardless of sex, in all infants not receiving $\mathrm{Fe}, \mathrm{Fe}$ status was poor at the age of 11 months, with over $50 \%$ of these infants having ferritin concentrations $<20 \mu \mathrm{g} / \mathrm{l}$. Daily supplementation with $10 \mathrm{mg} \mathrm{Fe}$ was sufficient to virtually eliminate Fe deficiency anaemia. Therefore, in view of the high risk of Fe deficiency, not only in boy infants but also in girl infants, and the serious consequences of Fe deficiency for psycho-motor development, action is urgently needed. Strategies to improve Fe status in infants during the first years of life, including fortification of infant foods and perhaps even supplementation, are urgently needed in South-East Asia.

\section{Acknowledgements}

We thank all mothers and infants involved in this study, and UNICEF for funding the study. UNICEF did not participate in the analysis of the data or in the writing of the manuscript. All authors were principal investigators at their study site, contributing to the core-protocol and overseeing collection and entering of data. F.T.W and M.A.D were responsible for pooling of the data and data analysis, and drafting of the first draft. All authors contributed to the final manuscript.

Other contributors were involved in the SEAMTIZI Study Group as follows: UI Study site: Utomo B, Krause V, Sunawang and Dibley M; INMU Study site: Yamborisut U, Chitchumroonchokchai $\mathrm{C}$, Thamrongvaranggoon $\mathrm{T}$, Thasanasuwan W, Rojroongwasinkul, Russameesopaphorn W, Boonpraderm A, Sranacharoenpong K and Pongcharoen T; NIN study site: Trung NQ, Nhien NV, Lien DK, Quyen DT, Hien VT, Thu NN, Khan NC, Khoi $\mathrm{HH}$ and Tolvanen M; NRDC study site: West $\mathrm{CE} \dagger$, Muhilal, Martuti S, Muhardiyantisih and
Permeasih D; UNICEF: Shrimpton R, Gross R†, Yip R, Schultink W, Darnton-Hill I and Esrey $\mathrm{S} \dagger$.

(† indicates deceased.)

\section{References}

1. UNICEF/UNU/WHO/MI (1999) Preventing iron deficiency in women and children. Technical consensus on key issues. Boston, MA: International Nutrition Foundation.

2. Allen LH (1994) Nutritional influences on linear growth: a general review. Eur J Clin Nutr 48, Suppl. 1, S75-S89.

3. Pollitt E (1999) Early iron deficiency anemia and later mental retardation. Am J Clin Nutr 69, 4-5.

4. Pollitt E, Watkins WE \& Husaini MA (1997) Three-month nutritional supplementation in Indonesian infants and toddlers benefits memory function 8 y later. Am J Clin Nutr 66, 1357-1363.

5. Grantham-McGregor SM \& Ani C (2001) A review of studies on the effect of iron deficiency on cognitive development in children. $J$ Nutr 131, 649S-668S.

6. Sherriff A, Emond A, Bell JC \& Golding J (2001) Should infants be screened for anaemia? A prospective study investigating the relation between haemoglobin at 8,12 , and 18 months and development at 18 months. Arch Dis Child 84, 480-485.

7. Dijkhuizen MA, Wieringa FT, West CE, Muherdiyantiningsih \& Muhilal (2001) Concurrent micronutrient deficiencies in lactating mothers and their infants in Indonesia. Am J Clin Nutr 73, 786-791.

8. Whittaker P (1998) Iron and zinc interactions in humans. Am J Clin Nutr 68, 442S-446S.

9. Dewey KG, Domellof M, Cohen RJ, Landa Rivera L, Hernell O \& Lonnerdal B (2002) Iron supplementation affects growth and morbidity of breast-fed infants: results of a randomized trial in Sweden and Honduras. J Nutr 132, 3249-3255.

10. Oppenheimer SJ (2001) Iron and its relation to immunity and infectious disease. J Nutr 131, 616S-635S.

11. Sazawal S, Black RE, Ramsan M, et al. (2006) Effects of routine prophylactic supplementation with iron and folic acid on admission to hospital and mortality in preschool children in a high malaria transmission setting: community-based, randomised, placebo-controlled trial. Lancet 367, 133-143.

12. Domellof M, Lonnerdal B, Dewey KG, Cohen RJ, Rivera LL \& Hernell O (2002) Sex differences in iron status during infancy. Pediatrics 110, 545-552.

13. Sherriff A, Emond A, Hawkins N \& Golding J (1999) Haemoglobin and ferritin concentrations in children aged 12 and 18 months. ALSPAC Children in Focus Study Team. Arch Dis Child 80, 153-157. 
14. Wasantwisut E, Winichagoon $\mathrm{P}$, Chitchumroonchokchai C, Yamborisut U, Boonpraderm A, Pongcharoen T, Sranacharoenpong K \& Russameesopaphorn W (2006) Iron and zinc supplementation improved iron and zinc status, but not physical growth, of apparently healthy, breast-fed infants in rural communities of northeast Thailand. J Nutr 136, 2405-2411.

15. Berger J, Ninh NX, Khan NC, Nhien NV, Lien DK, Trung NQ \& Khoi HH (2006) Efficacy of combined iron and zinc supplementation on micronutrient status and growth in Vietnamese infants. Eur J Clin 60, 443-454.

16. Nguyen XN, Berger J, Dao TQ, Nguyen CK, Traissac P \& Ha HK (2002) Efficacy of daily and weekly iron supplementation for the control of iron deficiency anaemia in infants in rural Vietnam. Sante 12, 31-37.

17. Dijkhuizen MA, Wieringa FT, West CE, Martuti S \& Muhilal (2001) Effects of iron and zinc supplementation in Indonesian infants on micronutrient status and growth. J Nutr 131, 2860-2865.

18. Gibson RS (1990) Principles of nutritional assessment. Oxford: Oxford University Press.

19. Wieringa FT, Berger J, Dijkhuizen MA, Hidayat A, Ninh NX, Utomo B, Wasantwisut E \& Winichagoon P (2007) Combined iron and zinc supplementation in infants improved iron and zinc status, but interactions reduced efficacy in a multicountry trial in southeast Asia. J Nutr 137, 466-471.

20. UNICEF (2005) The State of the World's Children 2006. New York: UNICEF.

21. Institute of Medicine (2000) Dietary Reference Intakes for Vitamin C, Vitamin E, Selenium, and Carotenoids. Washington, D.C.: National Academy Press.
22. Joint FAO/WHO Expert Consultation (2002) Vitamin and mineral requirements in human nutrition. Geneva, Switzerland: World Health Organization.

23. Lutter CK \& Dewey KG (2003) Proposed nutrient composition for fortified complementary foods. J Nutr 133, 3011S-3020S.

24. Sharieff W, Zlotkin S, Tondeur M, Feldman B \& Tomlinson G (2006) Physiologic mechanisms can predict hematologic responses to iron supplements in growing children: a computer simulation model. Am J Clin Nutr 83, 681-687.

25. Tondeur MC, Schauer CS, Christofides AL, Asante KP, Newton S, Serfass RE \& Zlotkin SH (2004) Determination of iron absorption from intrinsically labeled microencapsulated ferrous fumarate (sprinkles) in infants with different iron and hematologic status by using a dual-stable-isotope method. Am J Clin Nutr 80, $1436-1444$.

26. Thurlow RA, Winichagoon $\mathrm{P}$, Green $\mathrm{T}$, Wasantwisut $\mathrm{E}$, Pongcharoen T, Bailey KB \& Gibson RS (2005) Only a small proportion of anemia in northeast Thai schoolchildren is associated with iron deficiency. Am J Clin Nutr 82, 380-387.

27. Weatherall DJ \& Clegg JB (2001) Inherited haemoglobin disorders: an increasing global health problem. Bull WHO 79, 704-712.

28. Suharno D, West CE, Muhilal, Karyadi D \& Hautvast JG (1993) Supplementation with vitamin A and iron for nutritional anaemia in pregnant women in West Java, Indonesia. Lancet 342, $1325-1328$.

29. Wieringa FT, Dijkhuizen MA, West CE, Northrop-Clewes CA \& Muhilal (2002) Estimation of the effect of the acute phase response on indicators of micronutrient status in Indonesian infants. Journal of Nutrition 132, 3061-3066. 